\title{
0 rei da Assíria deseja ser um grande rei: tradução e comentário à carta EA 15
}

\section{The King of Assyria wishes to Become a Great King: EA 15 - A Portuguese Translation and Commentary}

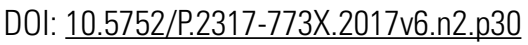

1. Bolsista Pós-Doutor, North-West University, África do Sul. Investigador Integrado, OBservare na Universidade Autónoma de Lisboa, Portugal. Professor Doutor Assistente, Universidade Presbiteriana Mackenzie. ORCID ID: 0000-0002-4072-1924.
Lucas G. Freire

Recebido em 01 de novembro de 2017 Aprovado em 10 de dezembro de 2017

\section{Resumo}

O presente artigo oferece, pela primeira vez em língua portuguesa, uma tradução do documento do arquivo de tabuletas de El-Amarna (EA 15) diretamente do original em acadiano. Essa tradução é seguida de um comentário textual e político à carta em questão, enquadrada numa abordagem teórica própria da disciplina de Relações Internacionais (RI). A carta EA 15 marca a ascensão da Assíria ao seleto grupo de unidades políticas com prerrogativas hegemônicas no sistema Amarna. A interpretação defendida aqui é discutida à luz dos estudos apresentados no simpósio interdisciplinar Amarna Diplomacy, editados por Raymond Cohen e Raymond Westbrook e publicado em 2000.

Palavras-chave: sociedade internacional; hierarquia e sistema suserano de estados; teoria de Relações Internacionais (RI) - Escola Inglesa; assiriologia Cartas de Amarna.

\section{AbSTRACT}

This article provides for the first time a Portuguese translation of Amarna letter EA 15 from the Akkadian original. The translation is followed by a textual and political commentary embedded in a theoretical approach borrowed from the field of International Relations. Letter EA 15 marks the rise of Assyria to the selective group of political units with hegemonic prerogatives in the Amarna system. The interpretation defended in this article is discussed in light of the studies presented at the interdisciplinary symposium Amarna Diplomacy, edited by Raymond Cohen and Raymond Westbrook and published in 2000.

Keywords: international society; hierarchy and suzerain system of states; IR theory - English School; Assyriology - Amarna Letters. 
Introdução

Os arquivos de tabuletas cuneiformes contendo mensagens enviadas por vários reis e líderes do antigo Oriente Próximo ao faraó egípcio formam um riquíssimo arquivo de fontes primárias para o estudo histórico das relações entre unidades políticas. As cartas de Amarna são um testemunho da complexidade dessas relações no sistema que se desenvolveu, naquela região, ao final da Era do Bronze (COHEN, 1996). Dentre elas, duas cartas da Assíria (EA 15 e EA 16) são indicativas duma ascensão, por parte da Assíria, ao grupo seleto de unidades políticas controladas por líderes rotulados de 'grandes reis' que se viam como 'irmãos' (PODANY, 2012). Na primeira (EA 15), o rei Aššur-uballiṭ I escreve que, até então, nenhum de seus antecessores tinha correspondido com o Egito. Na segunda (EA 16), que foi enviada certamente mais tarde, o mesmo rei já se vê à vontade para saudar o faraó como "meu irmão" (ŠEŠ-ia) e criticar o presente cerimonial que lhe havia sido enviado do Egito (EA 16: 13-18). A comparação entre EA 15 e EA 16 evidencia o sucesso do rei assírio em obter o status de grande rei.

O presente artigo ${ }^{2}$ oferece, pela primeira vez em língua portuguesa, uma tradução do documento EA 15 diretamente do original em acadiano. Essa tradução é seguida de um comentário textual e político à carta em questão, enquadrada numa abordagem teórica própria da disciplina de Relações Internacionais (RI). Trata-se dum exercício raro de interdisciplinaridade entre RI e Assiriologia, o campo entre Filologia e História Antiga dedicado à análise de textos do antigo Oriente Próximo. Além do diálogo com a literatura teórica em RI, também procuro interagir com alguns dos escritos contidos no volume Amarna Diplomacy, editado por Raymond Cohen e Raymond Westbrook (2000). Ora, é nessa e em nenhuma outra publicação que se vê um exercício semelhante de diálogo entre RI e Assiriologia com a ênfase principal recaindo justamente sobre os documentos de Amarna. Fica, então, mais do que justificada essa interação pormenorizada com argumentos particulares desenvolvidos em Amarna Diplomacy.

\section{Tradução}

Textos em escrita cuneiforme foram elaborados em vários idiomas. O texto em questão, EA 15, foi escrito numa variante do acadiano que possui algumas particularidades típicas do contexto assírio da segunda metade do segundo milênio a.C. (RAINEY, 2015, II, p. 1347). Na escrita cuneiforme acadiana, um símbolo pode representar uma sílaba (fonograma), um determinativo (que não é lido, mas que indica visualmente a classe de palavras à qual a palavra anterior ou seguinte pertence, como, por exemplo, se é um nome pessoal, ou nome duma cidade, e assim por diante). Pode, também, representar uma palavra inteira na língua suméria (ou sumerograma, o que permitia ao escriba economizar tempo e esforço ao usar apenas um símbolo no lugar de vários fonogramas para escrever a mesma palavra), que era lida com o som da palavra compreendida como equivalente em acadiano, e não em sumério. Além disso, alguns fonogramas podem servir
2. A pesquisa para este artigo foi em parte financiada pela bolsa de pós-doutoramento da Faculdade de Humanas da North-West University. Também o RCAC/ANAMED (Centro de Pesquisas em Civilizações da Anatólia) da Koç University em Istanbul contribuiu para tornar possível uma estadia de pesquisa na Turquia em Julho-Agosto de 2017. Ali, pude participar do treinamento em epigrafia cuneiforme na Seção Oriental do Museu Arqueológico de Istanbul. Desejo registrar meu profundo agradecimento a essas instituições e seus professores. 
3. Nesta linha corrigi, da transcrição de Rainey (2015, l, p. 128), o que é obviamente um erro de digitação de complementos fonéticos emendados a um sumerograma (para indicar a terminação da palavra, o que facilitava a identificação do caso gramatical) (HUEHNERGARD, 2011, pp. 68-74; 107-112).

Fontes primárias em Assiriologia são publicadas na forma de desenhos (ou cópias), fotografias, transcrições (que representam cada símbolo usando o alfabeto latino), normalizações (que reconstroem o texto com base em suas características linguísticas, e não com base numa mera correspondência entre os símbolos e o alfabeto latino) e traduções (geralmente, incluindo comentários a passagens difíceis ou ambíguas). O estudo proposto aqui oferece a mais recente transcrição (aquela publicada por Anson Rainey em 2015 a partir de contato recente e direto com a tabuleta), uma normalização e, finalmente, uma tradução para a língua portuguesa. Na transcrição abaixo, os fonogramas e complementos fonéticos são apresentados em itálico, os sumerogramas em letras maiúsculas e os determinativos, em letras acima da linha. Na transcrição, cada símbolo é separado, por um hífen, do símbolo seguinte dentro da mesma palavra. A tradução indica aproximadamente onde o texto foi danificado. Essas são práticas normais no campo de Assiriologia, permitindo uma ideia acurada, na ausência de uma fotografia ou cópia detalhada, de como os símbolos figuram na tabuleta (HUEHNERGARD e WOODS, 2008, pp. 88-90). O texto está dividido em linhas conforme aparece no objeto original.

O texto EA 15 está contido na tabuleta 24.2.11 do Metropolitan Museum of Art em Nova Iorque. Um desenho pioneiro detalhando o texto foi feito por Vincent Scheil (1902, p. 114), mas uma cópia mais recente pode ser encontrada na edição de Ira Spar (1988, ver ilustrações 112-113). Algumas transliterações anteriores à utilizada aqui são as de Pinhas Artzi (1978) e de William Moran (1988, pp. 149f). O próprio Moran (1992, pp. 3738) apresentou outra tradução inglesa do documento EA 15 junto às demais Cartas de Amarna. A publicação de Rainey ainda não tomou o lugar da tradução de Moran como a mais difundida em estudos secundários:

Transcrição (RAINEY, 2015, I, p. 128):

\begin{tabular}{|c|c|c|}
\hline Frente & 1 & $a-n a$ LUGAL KUR $M[i-i s ̦-(s a)-r i]$ \\
\hline & 2 & $q i-b i-[m a]$ \\
\hline & 3 & $u m-m a^{\mathrm{Id}} A-\check{s} u r$-TI.L[A LUGAL KUR $\left.{ }^{\mathrm{d}} A\right]$-šur-ma \\
\hline & 4 & $a-n a$ ka-ša É-ka a-na [KU]R-ka \\
\hline & 5 & $a-n a$ GIŠ.GIGIR.MEŠ- $k a$ ì ERÍN.MEŠ- $k a$ \\
\hline & 6 & $l u-u ́ s \check{s} u l-m u$ \\
\hline & 7 & DUMU ši-ip-ri-ia al-tap-ra-ak-ku \\
\hline & 8 & a-na a-ma-ri-ka ù KUR-ka a-na a-ma-ri \\
\hline & 9 & $a-d i a n-n i-\check{s} a a b-b a-u ́-i a$ \\
\hline & 10 & la ǐs-pu-ru \\
\hline & 11 & $u_{4}-m a$ a-na-ku al-tap-ra-ak-ku \\
\hline & 12 & 1 GIŠ.GIGIR ${ }^{3}$ SIG $_{5}$-ta 2 ANŠE.KUR.RA.MEŠ \\
\hline & 13 & 'ù' 1 NA4ú-hri-na ša NA $. Z A . G I ̀ N ~ K U R-e$ \\
\hline & 14 & {$[a-n] a \check{s} u l-m a-n i-k a$} \\
\hline & 15 & {$[\dot{u}]-\check{s} e-b i-l a-\left\ulcorner k u^{\top}\right.$} \\
\hline Lado & 16 & [DUMU ši]-ip-ri ša a $\check{s}-p u-r a-k u-n i$ \\
\hline
\end{tabular}




\begin{tabular}{|c|c|c|}
\hline \multirow{2}{*}{ Verso } & 17 & {$[a-] n a$ a-ma-ri } \\
\hline & 18 & {$[l] a t u_{4}-k a-{ }^{\ulcorner} a s^{\top}-s u ́$} \\
\hline & 19 & {$[l] i-m u-u r$ ù li-it-tal-ka } \\
\hline & 20 & [t]é-em-ka ù țé-em \\
\hline & 21 & $m a-t i-k a ~ l i-m u r$ \\
\hline & 22 & ù li-it-ta-al-ka \\
\hline
\end{tabular}

Normalização

(Linhas 1-6)

ana šar māt Mișșari qibi-ma

umma ${ }^{\mathrm{Id}}$ A ̌̌šur-uballit šar māt ${ }^{\mathrm{d}}$ A ̌̌šur-ma

ana kâša bìtīka ana mātīka ana narkabātīka u șābīka

lū šulmū

(Linhas 7-15)

mār šiprīya altaprakku ana amārīka u mātka ana amāri

adi anniša abba'ūya lā išpurū

ūma anāku altaprakku

1 narkabta banita 2 sisê u 1 uhinna ša uqnē šadî

ana šulmānīka ušēbilakku

(Linhas 16-22)

mār šiprīya ša ašpurakkunni ana amāri lā tukassu

lìmur u littalka tẹmka u țēm mātīka lìmur u littalka

Tradução

${ }^{1-3}$ Ao rei da terra do E[gito], diz:

"Assim (diz) Assur-ubal[lit, rei da terra de As]sur:"

${ }^{4-6} \mathrm{~A}$ ti, tua casa, ao teu [pa]ís, às tuas carruagens e exércitos, vá tudo bem!

${ }^{7-11}$ Envio-te meu mensageiro para te encontrar e para dar uma olhada em teu país. Até agora meus ancestrais não te haviam escrito. Hoje, eu próprio te escrevo. ${ }^{12-15}$ Mandei entregar- ${ }^{\top t e}{ }^{\top}$, [com] teus presentes de saudação, 1 carruagem bem-feita, 2 cavalos ${ }^{\top} \mathrm{e}^{\top} 1$ pedra de lápis-lazúli legítimo, (em forma de) tâmara. ${ }^{16-22}$ [O mensa]geiro que te enviei [pa]ra um encontro - [n]ão o de ${ }^{\Gamma t e^{1}}$ nhas! [Qu]e ele dê uma olhada e que venha embora. [Qu]e ele averigue a tua [situ]ação e a situação de teu país e que venha embora.

Comentário textual

A estrutura da mensagem não segue o modelo padrão de mensagens que pressupunham paridade entre remetente e destinatário. No entanto, como o texto deixa claro, esta mensagem tem o intuito de estabelecer o rei da Assíria como um membro no seleto grupo de grandes reis, o que viabilizará para ele os privilégios de paridade com os outros grandes reis, incluindo o faraó egípcio. Numa mensagem que pressupõe paridade, o remetente indica o nome do destinatário com a fórmula "ao Fulano (remetente), diz" (ana PNI qibi-ma), assim como nesta carta. Porém, ao identificar o destinatário, acrescenta: "assim (diz) Sicrano, grande rei, rei 
4. Christer Jönsson (2000, p. 193 comenta: "a linguagem das Cartas de Amarna é ritualizada, repleta de cortesias e outras frases padrão, sugerindo um código [...] bem estabelecido"

5. Exemplo: "Ao rei, meu senhor, meu deus, meu Sol" (ana šarrī bēliya, DINGIR. MEŠ-nu-ia u Šamšĩya) em EA 283: 1-3, enviada por Šuwardata, rei de Gath.

6. Como em sumério, a língua acadiana emprega determinativos, símbolos que esclarecem a categoria à qual a palavra marcada pelo símbolo pertence. No caso, Assur é marcado pelo determinativo de deidade. Determinativos eram indicadores visuais e não eram lidos como palavras separadas. Por critérios linguísticos, portanto, a preferência por eliminar a palavra "deus" da tradução fica justificada. 0 mesmo poderia ser dito acerca da palavra "terra" nas linhas $1-3$, porém a situação aqui é mais ambígua, uma vez que o nome Assur (marcado tanto pelo determinativo de deidade como pelo determinativo geográfico) pode indicar país, mas o mesmo nome (marcado pelo determinativo de deidade e pelo determinativo de cidade) pode indicar meramente a cidade de Assur. Mencionar o determinativo geográfico como "terra" na tradução diminui a ambiguidade potencial.

7. 0 mesmo rei que escreve EA 15 reclama em outra carta (EA 16: 22-25) que recebeu muito menos ouro que seu "antepassado" (abī, "meu pai" no original) tinha recebido quando escreveu

ao Egito (ana KUR Misri išpuru). Essa alegação pressupõe a existência prévia de comunicação entre os dois lados.

Carlo Zaccagnini (2000, p. 150) adota uma outra interpretação, afirmando que EA 16 mente sobre tal contato prévio a fim de barganhar. da terra de NG, teu irmão" (umma PN2 šarru rabû šar māt GN ahūka-ma, ver, por exemplo, EA 1: 2-3), o que não ocorre aqui. O objetivo central desta mensagem é estabelecer relações de paridade com o faraó, porém, sem antes presumir que ambos os líderes já se encontram no mesmo nível. É preciso que o rei assírio seja reconhecido como membro do seleto 'clube'. Outra indicação do tacto com que a carta foi composta é a ausência de qualquer relato sobre o bem-estar do remetente, e uma ênfase em desejar o bem-estar do destinatário. Os reis subordinados faziam desta forma na sua comunicação com seus respectivos superiores (MORAN, 1992, p. xxix). Esta carta, portanto, foi cuidadosamente composta numa roupagem de mensagem "assimétrica", embora tivesse o objetivo de elevar o status do rei assírio à posição de grande rei. ${ }^{4}$

Linhas 1-3. É notório que o faraó egípcio seja chamado simplesmente pelo seu título, "rei da terra do Egito" (šar māt Mișșari), enquanto reis subordinados se dirigem ao faraó utilizando uma terminologia mais hierárquica. ${ }^{5}$ Em seguida, o imperativo "diz" (linha 2, qibi-ma), padrão em cartas do período, revela um pouco de como a troca de mensagens era efetuada. O papel do escriba e do mensageiro se entrelaçam aqui. O texto é provavelmente apenas um lembrete das linhas gerais da mensagem, que o escriba anota como se tivesse recebido um ditado do remetente. A ordem "diz!" é dirigida ao leitor que lerá a carta em voz alta, uma vez que tenha chegado ao destino final. É muito provável, dada a brevidade dessas cartas, que o mensageiro tenha também a missão de esclarecer ou explicar melhor os vários componentes da mensagem (MEIER, 1988; MYNAROVA, 2007, p. 92; TARAWNEH, 2011, p. 271-277). A introdução da carta revela a identidade do remetente, Aššur-uballiț, "rei da Assíria" (linha 3, šar māt $\left.{ }^{\mathrm{d}} A \check{s} s ̌ u r\right)$. A expressão poderia ser traduzida como "rei da terra do deus Assur", o que revela um aspecto interessante sobre a identificação entre o deus-patrono assírio e a própria cidade principal daquele reino. Contudo, é evidente que o sentido aqui é de nomear a localidade, e não de descrevê-la como uma terra genérica que possui a característica de ser regida por aquele deus específico. Por isso, a tradução "rei da Assíria" é mais precisa. ${ }^{6}$

Linhas 4-6. Esta passagem é a saudação, desejando o bem-estar do rei e ampliando essa saudação para que também se aplique à própria família do rei, ao seu país, às suas carruagens e às suas tropas (linhas 4-5). A linha 6 é o precativo "que estejam bem" (lū šulmū), complementando essa saudação. Jana Mynarova (2007, pp. 105, 112) compara centenas de saudações nos arquivos de Amarna e nota que esta passagem particular no documento EA 15, juntamente com a outra carta assíria (EA 16) e uma terceira carta de outra proveniência (EA 12) são as únicas seguindo precisamente essa estrutura, formando, portanto, um subtipo de saudação com apenas três exemplos atestados, mas prefere evitar conclusões precipitadas com base somente na estrutura textual. Mesmo assim, fica clara na comparação que esta é uma passagem formal que segue certas convenções de redação e protocolo.

Linhas 7-11. Aqui começa a substância da mensagem. O rei assírio revê brevemente o histórico das relações diretas entre as duas unidades políticas, afirmando, com certo exagero, que seus antepassados não se comunicaram diretamente com o Egito (linhas 9-10). Agora, o rei assí- 
rio deseja estabelecer relações diretas com o faraó (linha 11). Foi por isso que enviou seu mensageiro no intuito de averiguar a situação do local e encontrar-se com o líder egípcio (linhas 7-8). O verbo utilizado, amāru, tem diversas conotações, dentre elas, a de "ver" ou "encontrar" (CAD A, parte 2, p. 5). Quando descreve a missão do mensageiro em relação ao local, a preferência foi por traduzi-lo no primeiro sentido. Quando se refere ao que o mensageiro deve fazer em conjunto com o faraó, a opção foi pela segunda alternativa. No original, essas linhas formam um eco, destacando a dupla missão do mensageiro.

Linhas 12-15. Como parte do protocolo, um presente de saudação (šulmānu) é enviado. Constam aqui dois cavalos, uma carruagem "bem-feita" (a palavra, derivada do verbo "fazer" ou "construir", também pode significar "bela") e uma pedra de lápis-lazúli "legítimo" (literalmente "lápis-lazúli da montanha" uqnē šadî) que lembra uma "tâmara" (a palara uhinnu dá nome à fruta, mas o determinativo $\mathrm{NA}_{4}$ revela que se trata duma pedra). Esses presentes são esclarecidos pela descrição que EA 16 faz, ligeiramente diferente, mas paralela, de outros presentes enviados também pela Assíria. Nesse outro texto, os novos cavalos são descritos como "brancos" (bem valiosos na época, segundo MORAN, 1992, p. 40, n. 3) e, em vez duma pedra-tâmara de legítimo lápis-lazúli, figura um "selo" ( $\left.{ }^{\mathrm{na}} \mathrm{K} \mathrm{KIŠIB}\right)$ do mesmo material. A oposição nas Cartas de Amarna entre o lápis-lazúli "da montanha" (šadî) e uma imitação feita de vidro é investigada por Mynarova (2012). Parece que a mera grafia da palavra uqnī com o complemento šadî não garante necessariamente que o objeto referido não tenha sido uma imitação.

Linhas 16-22. O final da mensagem é um esclarecimento a respeito da missão do mensageiro (mār šipru, literalmente, "filho do envio"). Ele deve observar ou visitar a terra de faraó (como visto, amāru pode ter os dois sentidos) e, mais especificamente, a situação na corte e no local (o termo aqui é tẹmu, que em diversos textos tem a conotação de "relatório" ou "notícia”). A tradução preferida por Rainey (2015, I, p. 129) é "natureza" ou "comportamento". Optei, aqui, por "situação", que é um termo mais próximo do uso comum com o sentido de "notícia". Essa explicação do dever atribuído ao mensageiro assírio é seguida de um enfático pedido: "não o detenhas!" Este verbo (kalû) também é usado no sentido de "atrasar" (CAD ${ }^{8}$, p. 96). O mensageiro deve cumprir sua missão e retornar (alāku com o sufixo ventivo $-a$ ) ao rei assírio. O pedido pelo retorno do mensageiro é reiterado mais uma vez, como parte do pedido final. Ele deve cumprir a missão de observar a situação no Egito e, então, regressar.

Comentário político

Aššur-uballiț I, que chegou ao poder em meados do século XIV a.C., aproveitou-se do declínio de Mittani, o país que havia por várias décadas controlado a Assíria. O líder assírio quebrou o pacto que seu país tinha com Mittani ao fazer uma aliança bem sucedida contra aquela potência em declínio. A terra de Mittani jamais foi a mesma, e a Assíria viu-se livre para ingressar no mundo das grandes potências de então (JAKOB, 2017, p. 117). Ao comentar a carta EA 15, Moran (1988, p. 150) declara:
8. Volume do Assyrian Dictionary of the Oriental Institute of the University of Chicago. 
Tanto o uso do título de 'rei' como a designação da Assíria como um país e não simplesmente uma cidade parecem ser inovações de Aššur-uballiṭ. Com um novo senso de unidade e propósito político, a Assíria está prestes a inaugurar se novo papel na história do Próximo Oriente.

Por que marcar a ascensão a um novo papel nas relações internacionais com esta mensagem ao faraó egípcio? Uma breve explicação sobre as estruturas e convenções políticas daquele sistema aponta o rumo de uma possível resposta.

Para começar, embora não tenhamos um arquivo contínuo documentando todo o segundo milênio a.C., podemos examinar as estruturas e convenções do período Amarna à luz da ampla documentação do período paleo-babilônico, séculos antes, quando a violência era "endêmica”, porém, "os reis não eram sem lei” (SASSON, 2015, p. 344). Já naquele sistema, havia a noção de uma sociedade de reis dividida em pelo menos duas camadas (Cohen, 2013, p. 16-17). Essa distinção é pressuposta, como indico alhures, também em documentos de meados do século XIV a.C., inclusive no período Amarna (FREIRE, 2013). Os atores mais poderosos do sistema eram classificados como 'grandes reis' e tinham prerrogativas comparáveis às da noção moderna de soberania e independência. Era preciso que grandes reis fossem reconhecidos como tais pelos demais atores do sistema. Um grande rei tinha, dentre outros objetivos na sua política externa, a tarefa de manter a ordem entre os demais reis e líderes sob sua proteção. Sua autoridade sobre uma esfera de influência específica era reconhecida na prática. Na camada inferior, os demais líderes interagiam primariamente com o grande rei que os liderava.

Esses líderes subordinados não tinham independência nas suas relações exteriores e precisavam seguir as diretrizes ditadas pelo grande rei. As convenções da época, embora ambíguas, pelo menos deixavam clara essa distinção entre as duas camadas. Membros da camada superior se chamavam de 'irmão' $(a h u)$. Entre uma camada e outra, o líder subordinado deveria mostrar deferência. Era comum um líder subordinado se referir a um grande rei como 'pai' ( $a b u$ ). A escassez de documentação das relações exteriores nos séculos que separam os períodos paleo-babilônico e Amarna não nos permite postular de forma dogmática uma continuidade absoluta nas estruturas e convenções políticas entre um e outro. Porém, até certo ponto é possível inferir que os arquivos de Amarna denotam um refinamento de práticas anteriores - de normas e interações estruturadas por uma sociedade na qual grandes reis interagem com outros grandes reis e também com líderes subordinados (RAGIONIERI 2000, p. 42-50).

Em termos próprios à teoria de RI, podemos classificar a relação entre um grande rei e seus subordinados no exterior como uma relação de hegemonia e, em diversos casos, até mesmo de domínio. Contrastando esses dois tipos ideais de relações bilaterais, Adam Watson (2007, p. 2021) atribui à hegemonia uma situação de relativa independência entre os atores do sistema, sendo que um ator mais poderoso tem a capacidade de ditar certos aspectos de como o sistema em si opera. Já no caso da relação de domínio, essa capacidade também se estende à determinação, ainda que parcial, da política interna e externa dos outros atores por parte dum centro imperial. Se, entre os grandes reis, a relação tende à independên- 
cia, no caso da díade entre um grande rei e um governante subordinado, essa relação pode ser classificada no contínuo entre hegemonia e domínio, dependendo da situação. Ora, já que cada rei tinha não somente um, mas vários reis subordinados, podemos dizer que cada grande rei liderava uma confederação ou "sistema suserano de estados", para usar o termo cunhado por Martin Wight (1977, p. 24).

A configuração do sistema Amarna é, segundo Wight (1977, p.25), "um exemplo virtualmente singular" do que ele chama de "sistema secundário de estados", definido como um sistema "cujos membros não são estados soberanos unitários em si mesmos, mas complexos impérios ou sistemas suseranos de estados". Creio, porém, que a categorização de Wight é incompleta, pois ela enfatiza a relação entre os grandes reis (cada um liderando uma confederação com seus respectivos subordinados), ignorando frequentes interações entre reis subordinados, dentro de sua confederação ou fora. Por isso, acho melhor falar em dois sistemas que coexistem e que se entrelaçam. Usando as categorias de Wight (1977, p. 22-23), podemos nomear cada um deles. Entre os grandes reis, configura-se, um "sistema de estados internacional" de unidades políticas relativamente autônomas.

Entre grandes reis e seus subordinados que lideram outras unidades políticas, temos um "sistema suserano de estados". O todo formado pelo entrelaçamento de ambas as partes continua a ser um sistema secundário de estados, se mantivermos a distinção feita mais recentemente por Barry Buzan (2014, p. 49) entre "sistemas primários de estados" onde "as unidades são estados" e "sistemas secundários de estados" onde as unidades são "sistemas primários de estados", deixando claro que Wight restringe sobremaneira a categoria ao defini-la somente como um conjunto de sistemas suseranos.

A carta EA 15 é bastante peculiar, no sentido de ser um dos poucos documentos descrevendo ou conotando a mudança de status de um ator no sistema. Nesse esquema conceitual a Assíria, liderada por Ǎšsur-uballit, desvencilhou-se da interferência direta de Mittani e se reposicionou no sistema ao abandonar o sistema suserano liderado por Mittani. Essa manobra foi possível por conta da quebra do pacto entre Assíria (na condição de subordinada) e Mittani, indicando a violação de uma das normas do sistema suserano (a do controle de sua política externa pelo polo imperial'). Porém, como Hedley Bull sabiamente coloca, mesmo uma regra eficaz de conduta é normalmente violada. Para ser eficaz, basta que uma regra seja "obedecida até certo ponto" e também "considerada como um fator nos cálculos daqueles a quem ela se aplica, mesmo daqueles que a decidem violar" (2012, p. 53). Ao enviar a carta EA 15, o rei assírio ao mesmo tempo quebra a norma que configura um sistema de duas 'camadas' (e que restringe a autonomia dos atores na camada inferior) e revigora seu apreço por essa própria norma constitucional, ao solicitar reconhecimento como um novo ator na camada superior (e, com ele, os privilégios de fazer parte do 'sistema de estados internacional').

Na sua substância, da linha 7 em diante, esse documento denota como a Assíria deseja uma nova era na sua política externa, estabelecendo comunicação com o envio de um mensageiro, enviando finos presentes 
9. Por que tal veemência nessa solicitação? A outra carta assíria enviada ao faraó (EA 16) implica uma possível resposta. No final da carta, o rei assírio pergunta qual é a utilidade de deixar mensageiros morrerem expostos ao sol ao invés de permitir que retornem (comparar RAINEY 2015, I, p. 133 e MORAN 1992, p. 39). Será que essa mensagem posterior alude a uma prática comum naquela época, possivelmente ligada ao culto ao deus do disco solar? Ou será que tem a ver primariamente com algum acontecimento isolado que os dois reis conhecem mas que, agora, é impossível recuperar na ausência de maiores detalhes? De toda forma, fica claro aqui que a jurisdição sobre o mensageiro cabe ao governante do lugar onde ele se encontra. cerimoniais de saudação e solicitando ao faraó que deixe o mensageiro retornar com informação. Com essa jogada, a Assíria efetivamente mostra que sabe cumprir normas e seguir uma tradição pré-estabelecida de troca de mensagens e presentes entre os grandes reis. Além disso, ela afirma indiretamente os valores que regem o sistema como um todo, ao reconhecer a jurisdição de faraó sobre seu território e sobre qualquer pessoa nele presente, inclusive o mensageiro assírio (uma prerrogativa que obviamente precede a norma da imunidade diplomática, desenvolvida só anos mais tarde). Por outro lado, a Assíria nessa carta também convida o Egito a reconhecê-la como novo membro na camada superior do sistema. Os presentes devem ser reciprocados (LIVERANI, 2000, p. 24-25) e o mensageiro deve ser bem tratado. ${ }^{9}$ A julgar pela saudação da carta EA 16 enviada provavelmente anos mais tarde por um Aššur-uballit de poder claramente demonstrado e consolidado, podemos inferir que tal reconhecimento de fato ocorreu. Nessa outra carta, o rei assírio se apresenta ao faraó como Ǎ̌šur-uballit šar māt ${ }^{d} A \check{s} \breve{s} u r ~ s ̌ a r r u ~ r a b \hat{u}$ ahūka "Aššur-uballit, rei da Assíria, Grande Rei, teu irmão” (EA 16: 3-4).

Discussão

Minha interpretação de EA 15 acrescenta uma nova dimensão conceitual à discussão do sistema Amarna. Os comentários de quem se debruçou sobre esta carta em diálogo com RI no simpósio Amarna Diplomacy tendem a confirmar a minha interpretação política, com algumas diferenças. A primeira delas é a questão da profundidade do elemento social no sistema Amarna. Rodolfo Ragionieri, com exagero, rotula aquele sistema como "a primeira sociedade internacional extensa e significante na história da humanidade” (2000, p. 42), notando (ainda que superficialmente) como o conceito de 'sistema secundário' aplicado e refinado acima poderia ser usado na interpretação das Cartas de Amarna. Ragionieri chega a apontar que diplomacia e guerra poderiam ser vistas como instituições dessa sociedade internacional (2000, p. 50-53). Porém, o autor desiste logo da ideia de uma aplicação mais sistemática da noção de sociedade internacional ao sistema Amarna com o argumento de que, naquele sistema, "os atores ainda estavam se ajustando uns aos outros" (RAGIONIERI, 2000, p. 43, 45). No presente artigo, procurei aplicar a teoria da sociedade internacional no ponto mais relevante à carta EA 15: a distinção entre duas camadas como norma constitucional e a necessidade de reconhecimento para obter acesso à camada superior com todas as suas prerrogativas. O leitor familiarizado com a teoria da sociedade internacional poderá perceber nessa minha ênfase certos temas em comum com a obra de Hedley Bull (2012), Christian Reus-Smit (1999) e C. A. W. Manning (1962), principalmente quando esses autores hierarquizam certas normas como fundamentos das demais normas e instituições duma sociedade internacional.

Ao contrário de Ragionieri, sugeri aqui que a comunicação entre reis pode ser vista como uma das práticas institucionalizadas do sistema Amarna, mas, como nota Geoffrey Berridge (2000) a inexistência de imunidade diplomática naquele contexto dificulta a atribuição do nome de 
'diplomacia' a essa prática. Por isso Raymond Westbrook (2000, p. 33) prefere usar o termo 'enviado' e eu, 'mensageiro', mas não 'diplomata'. Paul Sharp (2009, p. 62), por outro lado, parece não ter problemas com o rótulo aplicado ao sistema Amarna, mas se vê obrigado a reconhecer que a diplomacia pode tomar várias formas a depender do período histórico - talvez por adotar uma definição mais flexível do fenômeno (SHARP, 2009; LAFONT, 2001).

Não há espaço aqui para lidar com esse debate, mas sinto-me no dever de justificar minha opção por evitar o termo 'diplomacia' remetendo o leitor a um estudo anterior, onde identifiquei as instituições-base e também as instituições secundárias da sociedade de reis do segundo milênio a.C. (FREIRE, 2015). Naquele estudo, duas conclusões importantes foram tiradas. Primeiro, é possível aplicar a noção geral de uma ordem normativa e institucional entre unidades políticas com base na teoria da sociedade internacional. Acontece que, segundo, os detalhes a respeito de quais normas e instituições específicas foram empregadas na ordem do segundo milênio a.C. devem ser providos à luz da prática naquele contexto histórico. A lista bastante conhecida de instituições (incluindo a diplomacia) postuladas na obra de Bull deve ser revista nessa contextualização.

A segunda diferença entre a minha interpretação política da carta EA 15 e a de alguns integrantes do simpósio Amarna Diplomacy é o peso dado a fatores estratégicos e comerciais nesse documento em particular. Naquele simpósio, o assiriólogo Pinhas Artzi resumiu a significância histórica desse documento da seguinte forma:

Com [o faraó] Akhenaten e seus ministros, houve uma guinada crucial na política externa egípcia [em relação a Mittani]. Com o recebimento de uma delegação assíria, um ato equivalente à abertura de relações diplomáticas, a Assíria, participante ativa na destruição de Mittani, [...] era agora reconhecida como plenamente igual (ARTZI, 2000, p. 211).

Tenho motivos para qualificar a última frase, dada a visão política extremamente hierárquica do que os faraós tinham de si em relação ao resto da humanidade, mas alguma forma de reconhecimento da Assíria como um ator mais relevante foi buscada em EA 15 e subsequentemente obtida. Portanto, de resto, esse comentário vai no mesmo sentido do que eu propus acima. Isso significa que a ascensão da Assíria à camada superior do sistema é o tema central dessa carta. Outros autores no simpósio que comentaram EA 15 desviaram a atenção para tópicos que considero periféricos nesse caso específico. Steven David (2000, p. 59) se mostra deveras preocupado em achar relevância no conteúdo de EA 15 para o debate entre construtivistas e realistas em RI, reduzindo a utilidade da carta a uma mera manobra de inteligência para a Assíria, visto que o mensageiro deveria averiguar a situação política no Egito.

É seguro afirmar, como estudos históricos sobre o papel do mensageiro no antigo Oriente Próximo já mostraram, que parte de sua função era a de coletar informação (ver, por exemplo, MEIER, 1988). Porém, essa atribuição deve ser vista dentro do contexto mais amplo do papel da troca de mensagens. Carlo Zaccagnini (2000, p. 149) nota, corretamente, a intenção de estabelecer comunicação regular entre a Assíria e o Egito, mas acrescenta uma motivação comercial a essa comunicação. 
Penso que essa atribuição de motivo econômico carece de base textual em EA 15. É verdade que a Assíria envia presentes e espera receber outros bens em troca, e é verdade que a troca de presentes desempenhava uma certa função de escambo, porém o caráter protocolar dos presentes de saudação e a ansiedade da Assíria por cumprir uma norma institucionalizada é o que deve saltar à vista na interpretação política dessa carta específica. No simpósio, é Kevin Avruch (2000, p. 159) que nota melhor o envio dos presentes de saudação como um primeiro passo da Assíria rumo ao reconhecimento na camada superior do sistema.

Considerações finais

A carta EA 15, aqui traduzida, comentada e discutida, marca a ascensão do rei assírio ao status de grande rei e irmão de outros grandes reis. Ela marca o ingresso da Assíria à camada superior da sociedade de reis do antigo Oriente Próximo em meados do século XIV a.C. A mensagem foi cuidadosamente elaborada para retratar Aššur-uballit I, que acabara de romper com as normas do sistema suserano liderado por Mittani (a potência em declínio) como respeitador das normas do sistema geral, composto por vários sistemas suseranos. A partir de agora, a Assíria trataria de assegurar o seu direito a uma política livre de interferência externa. Num segundo momento, buscaria delimitar sua esfera de influência própria, como cabe a toda potência na camada superior do sistema. Obter o reconhecimento ao status de grande rei por parte do faraó egípcio foi um primeiro passo importante no sentido de consolidar a ambição assíria um marco da política externa de Aššur-uballit I.

Referências

ARTZI, P. The rise of the Middle-Assyrian kingdom according to El-Amarna letters 15 and 16: A contribution to the diplomatic history of the ancient Near East in the mid-second millennium BCE. In: ARTZI, P. (ed.) Bar-Ilan Studies in History. vol. 1, Ramat ,Gan: Bar-Ilan University Press, 1978. p. 25-41.

ARTZI, P. The diplomatic service in action: The Mittani file. In: COHEN, R.; WESTBROOK, R. (ed.) Amarna Diplomacy: The Beginnings of International Relations. Baltimore, MD: The Johns Hopkins University Press, 2000, cap. 16, p. 205-211.

AVRUCH, K. Reciprocity, equality, and status-anxiety in the Amarna letters. In: COHEN, R.; WESTBROOK, R. (ed.) Amarna Diplomacy: The Beginnings of International Relations. Baltimore, MD: The Johns Hopkins University Press, 2000, cap. 12, p. 154-164.

BERRIDGE, G. Amarna diplomacy: a full-fledged diplomatic system? In: COHEN, R.; WESTBROOK, R. (ed.) Amarna Diplomacy: The Beginnings of International Relations. Baltimore, MD: The Johns Hopkins University Press, 2000, cap. 17, p. 212-224.

BULL, H. The Anarchical Society: A Study of Order in World Politics. Basingstoke, Palgrave Macmillan, 2012.

BUZAN, B. An Introduction to the English School of International Relations: The Societal Approach. Cambridge, Polity, 2014.

BRINKMAN John; BIGGS Robert; CIVIL Miguel; FARBER Walter; REINER Erica; ROTH Martha; STOLPER Matthew. The Assyrian Dictionary of the Oriental Institute of the University of Chicago (CAD). Chicago, IL: University of Chicago, 2010.

COHEN, R. Diplomacy through the ages. In: KERR, P; WISEMAN, G. (ed.) Diplomacy in a Globalizing World: Theories and Practices. Oxford, Oxford University Press, 2013, cap. 1, p. 15-30. 
COHEN, R. On diplomacy in the ancient Near East: the Amarna letters. London, Diplomacy and Statecraft, v. 7, n. 2, p. 245-270, 1996.

COHEN, R. e WESTBROOK, R. (ed.) Amarna Diplomacy: The Beginnings of International Relations. Baltimore, MD: The Johns Hopkins University Press, 2000.

DAVID, S. R. Realism, constructivism, and the Amarna Letters. In: COHEN, R.; WESTBROOK, R. (ed.) Amarna Diplomacy: The Beginnings of International Relations. Baltimore, MD: The Johns Hopkins University Press, 2000, cap. 5, p. 54-67.

FREIRE, L. G. Covenant and international relations in the ancient Near East: A preliminary exploration. Antiguo Oriente, n. 11, p. 129-154, 2013.

FREIRE, L. G. System and society: The Near East in the second millennium BCE. In: $\mathbf{6 1}^{\text {st }}$ Rencontre Assyriologique Internationale. Genebra e Berna, 22-26 jun, 2015.

HUEHNERGARD, J. A Grammar of Akkadian. Winona Lake, In: Eisenbrauns, 2011.

HUEHNERGARD, J. e WOODS, C. Akkadian and Eblaite. In: WOODARD, R. D. (ed.) The Ancient Languages of Mesopotamia, Egypt, Aksum. Cambridge, Cambridge University Press, cap. 4, p. 83-152.

JAKOB, S. The Middle Assyrian period (1 $14^{\text {th }}$ to $11^{\text {th }}$ century BCE). In: FRAHM, E. (ed.) A Companion to Assyria. Malden, Wiley Blackwell, 2017, p. 117-142.

JÖNSSON, C. Diplomatic signaling in the Amarna letters. In: COHEN, R.; WESTBROOK, R. (ed.) Amarna Diplomacy: The Beginnings of International Relations. Baltimore, MD: The Johns Hopkins University Press, 2000, cap. 15, p. 191-204.

LAFONT, B. International relations in the ancient Near East: the birth of a complete diplomatic system. Diplomacy and Statecraft, v. 12, n. 1, p. 39-60, 2001.

LIVERANI, M. The Great Powers' club. In: COHEN, R.; WESTBROOK, R. (ed.) Amarna Diplomacy: The Beginnings of International Relations. Baltimore, MD: The Johns Hopkins University Press, 2000, cap. 2, p. 15-27.

MANNING, C. A. W. The Nature of International Society. London, G. Bell and Sons, 1962.

MEIER, S. A. The Messenger in the Ancient Semitic World. Atlanta, GA: Scholars Press, 1988.

MORAN, W. L. Amarna Texts (N. 102, 103). In: Spar, I. (ed.) Cuneiform Texts in the Metropolitan Museum of Art, v. 1: Tablets, Cones, and Bricks of the Third and Second Millennia BC. New York, The Metropolitan Museum of Art, 1988, p. 149-151.

MORAN, W. L. The Amarna Letters. Baltimore, MD: The Johns Hopkins University Press, 1992.

MYNAROVA, J. Language of Amarna - Language of Diplomacy: Perspectives on the Amarna Letters. Prague, Czech Institute of Egyptology, 2007.

MYNAROVA, J. From the mountain or from the kiln? Lapis lazuli in the Amarna Letters. In: del OLMO LETE, G.; VIDAL, J.; WYATT, N. (ed.) The Perfumes of Seven Tamarisks: Studies in Honour of Wilfred G. E. Watson. Münster, Ugarit-Verlag, 2012, p. 63-70.

OPPENHEIM, A. L. The Assyrian Dictionary of the Oriental Institute of the University of Chicago, Vol. 1 (A part II). Chicago, IL: The Oriental Institute, 1968.

OPPENHEIM, A. L. The Assyrian Dictionary of the Oriental Institute of the University of Chicago, Vol. 8 (K). Chicago, IL: The Oriental Institute, 1971.

PODANY, A. Brotherhood of Kings: How International Relations Shaped the Ancient Near East. Oxford, Oxford University Press, 2012.

RAGIONIERI, R. The Amarna age: an international society in the making. In: COHEN, R.; WESTBROOK, R. (ed.) Amarna Diplomacy: The Beginnings of International Relations. Baltimore, MD: The Johns Hopkins University Press, 2000, cap. 4, p. $42-53$.

RAINEY, A. F. (ed.) The El-Amarna Correspondence: A New Edition of the Cuneiform Letters from the Site of El-Amarna Based on Collations of All the Extant Tablets. Leiden, Brill, vol. 2, 2015.

REUS-SMIT, C. The Moral Purpose of the State: Culture, Social Identity, and Institutional Rationality in International Relations. Princeton, NJ: Princeton University Press, 1999.

SASSON, J. M. From the Mari Archives: An Anthology of Old Babylonian Letters. Winona Lake, IN: Eisenbrauns, 2015.

SCHEIL, V. Deux nouvelles lettres d'El Amarna, Bulletin de l'Institut Français d'Archéologie Orientale du Caire. Caire, v. 2, p. 113-118, 1902. 
SHARP, P. Diplomatic Theory of International Relations. Cambridge, Cambridge University Press, 2009.

SPAR, I. (ed.) Cuneiform Texts in the Metropolitan Museum of Art, v. 1: Tablets, Cones, and Bricks of the Third and Second Millennia BC. New York, The Metropolitan Museum of Art, 1988 .

TARAWNEH, H. Amarna Letters: Two Languages, Two Dialogues. In: MYNAROVA, J. (ed.) Egypt and the Near East - The Crossroads: Proceedings of an International Conference on the Relations of Egypt and the Near East in the Bronze Age. Prague, Charles University, 2011, p. 271-284.

WATSON, A. Hegemony and History. London, Routledge, 2007.

WESTBROOK, R. International Law in the Amarna Age. In: COHEN, R.; WESTBROOK, R. (ed.) Amarna Diplomacy: The Beginnings of International Relations. Baltimore, MD: The Johns Hopkins University Press, 2000, cap. 3, p. 28-41.

WIGHT, M. Systems of States. Leicester, Leicester University Press, 1977.

ZACCAGNINI, C. The interdependence of the great powers. In: COHEN, R.; WESTBROOK, R. (ed.) Amarna Diplomacy: The Beginnings of International Relations. Baltimore, MD: The Johns Hopkins University Press, 2000, cap. 11, p. 141-153. 